Case Report

\title{
Intra-Abdominal Localisation of a Buschke-Lowenstein Tumour: Case Presentation and Review of the Literature
}

\author{
N. E. Wester, E. M. Hutten, C. Krikke, and Robert A. Pol \\ Division of Transplantation Surgery, Department of Surgery, University Medical Center Groningen, University of Groningen, \\ P.O. Box 30 001, 9700 RB Groningen, The Netherlands
}

Correspondence should be addressed to Robert A. Pol; pol.chirurgie@gmail.com

Received 23 June 2013; Accepted 26 August 2013

Academic Editors: D. Capone, F. Keller, M. R. Moosa, and Y. Sugawara

Copyright (C) 2013 N. E. Wester et al. This is an open access article distributed under the Creative Commons Attribution License, which permits unrestricted use, distribution, and reproduction in any medium, provided the original work is properly cited.

\begin{abstract}
Giant condyloma acuminatum or Buschke-Lowenstein tumour is a very rare disease which usually is located in the genital, anorectal, and perianal regions. It is regarded as a type of verrucous carcinoma occurring on anogenital mucosal surfaces where it is locally invasive but displays a benign cytology. We describe a case of a 24-year-old woman with persisting condyloma acuminata progressing to a large intra-abdominal Buschke-Lowenstein tumour. To our knowledge such an advanced stage has only been reported once before. The severity and extent of the tumour both determine the treatment and patient outcome. Treatment was impeded by cachexia, an immunosuppressive state after kidney transplantation and difficulties in establishing a reliable diagnose. Interferon treatment was started which initially led to tumour reduction but was complicated by an interferon-induced pancreatitis, pneumonia, and fasciitis necroticans resulting in death. We present a literature overview on the treatment options for a BuschkeLowenstein tumour, with emphasis on interferon therapy, with all the advantages and disadvantages.
\end{abstract}

\section{Introduction}

Worldwide prevalence of human papilloma virus (HPV) is $10 \%$, mostly affecting women under the age of 35 [1]. The associated condylomata acuminata (CA) has an estimated prevalence of $0.75-3 \%$ in Europe and $1 \%$ in the United States [2]. One of the risk factors for $\mathrm{CA}$ is an immune-compromised state. On rare occasions progression to a Buschke-Lowenstein tumour (BLT) occurs. A BLT is a very rare, slowly growing, locally destructive, and infiltrative tumour associated with HPV types $6,11,16$, and 18 . Usually the tumour is located in the genital, anorectal, and perianal regions. Despite the benign histological characteristics of the tumour there is a high risk of recurrence and malignant transformation to squamous cell carcinoma (SCC), in particular for HPV types 16 and 18 [3-7]. Little is known about the true incidence rates of BLT due to the difficulties in histomorphological differentiation and thereby making the correct diagnosis. Current literature reports an increase to 6.3 cases per year in the last decade [8]. Due to this low incidence little is known about treatment outcomes, making comparison between various treatment regimens difficult.

To date only three papers are available reporting on, respectively, 42, 63, and 51 cases $[3,8,9]$ and one small review
[10]. They conclude that complete resection is the preferred initial therapy as it has the highest success rate and the lowest risk of recurrence. Contradictory is that surgery can be very mutilating as extensive resection is usually required due to ingrowth into local structures. Alternatively chemotherapy and radiation therapy have been described with varying results. However, in most cases, it proved to be difficult to determine a true malignancy so that there is a risk of overtreatment.

A possible alternative treatment may be interferon therapy as an effort to boost the patient's own immune system [116]. As a new and experimental treatment for targeting BLT, there are no large series available let alone randomized trials. The majority of available data comes from other case reports and small case series concerning CA [17-20]. We present a rare case and provide a literature overview on the treatment options for a BLT, with emphasis on interferon therapy.

\section{Case Presentation}

A 24-year-old cachectic female patient, with a status after kidney transplantation due to hemolytic-uremic syndrome in 2000, was referred to our university medical center because 
of persisting incapacitating CA under prolonged immunosuppressive therapy. Her initial immunosuppression regimen consisted of tacrolimus $5 \mathrm{mg}$ and prednisolone $7.5 \mathrm{mg}$ daily. At presentation in 2010 she suffered from severe CA located both intravaginal and perianal (Figure 1). This has led to excessive pain and defecation problems despite local and topical treatment by surgeons, gynaecologists, and dermatologists for over five years. Viral serology revealed the patient to be HPV-16 and HPV-18 positive. Her HIV status was negative. At our center multiple biopsies revealed serious dysplasia, and only one sample revealed malignant cells. Because of persistent lower back pain a MRI scan was performed. This showed a large process in the lower pelvic region with extension into the abdomen and cavum douglasi, consistent with the diagnosis intra-abdominally located BLT (Figure 2). Prior to presentation at our hospital, the patient already had, in vain, several surgical procedures to obtain local control. At presentation both the cachexia of the patient, the localisation and infiltration of the process made surgical treatment (anterior and posterior exenteration) no realistic option. As a malignancy could not be definitely established, radio- or chemotherapy was therefore not indicative. Because the tumour had centrally liquefied, resulting into abscesses, multiple drainage procedures were necessary. In order to treat the BLT the immunosuppressive therapy was lowered to $5 \mathrm{mg}$ prednisone daily, and interferon therapy was started as an effort to boost the patients' immune system $[12,15,16]$. After multidisciplinary consultation a dosage of $180 \mu \mathrm{g} /$ week interferon alfa $2 \mathrm{~B}$ was given by subcutaneous injections. After it became clear that the kidney function remained stable, the immunosuppressive therapy was further lowered to 5 and $2.5 \mathrm{mg}$ prednisolone every other day. Because of severe malnutrition and cachexia, the patient received gastric tube feeding. During the interferon therapy a new abscess arose in the lower back, which was found to have a direct relationship with the BLT. On a follow-up MRI and CT scan, respectively, two and four months after the first interferon injection, a reduction in tumour mass was visible. As a chance finding an interferon-induced pancreatitis was visible on the CT. There were no further adverse effects of the therapy. Based on the established tumour reduction, interferon therapy was continued. Unfortunately after four months of treatment the patient was readmitted to our hospital because of a pneumococcal pneumonia for which antibiotic therapy was started. During hospitalization the patient developed progressive pain in the lower back and left leg in combination with a septic profile. The diagnosis necrotizing fasciitis was made and due to the clinical condition of the patient, combined with the extent of the disease, the treatment was discontinued in agreement with the family and the patient died. Unfortunately no informed consent was obtained for a postmortem examination.

\section{Discussion}

This report underlines the impact and difficulties of treating BLT. Progression to an intra-abdominal mass even further complicates treatment and to date has been described only once. Early detection of abdominal involvement in combination with a reliable histopathological diagnosis is essential for

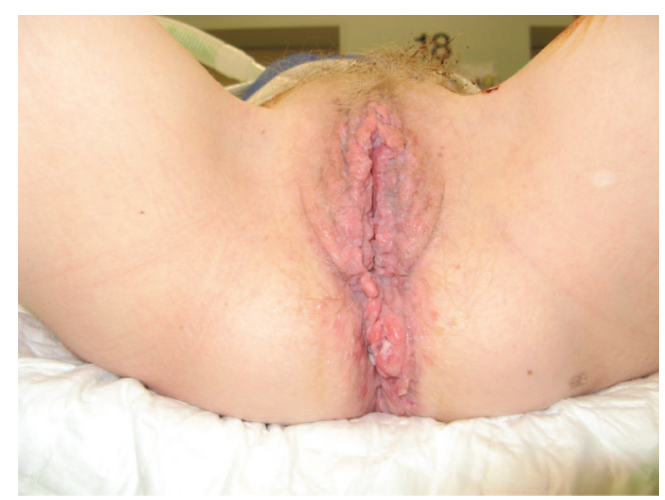

FIGURE 1: Extensive condyloma acuminata of the vulvar and perianal regions.

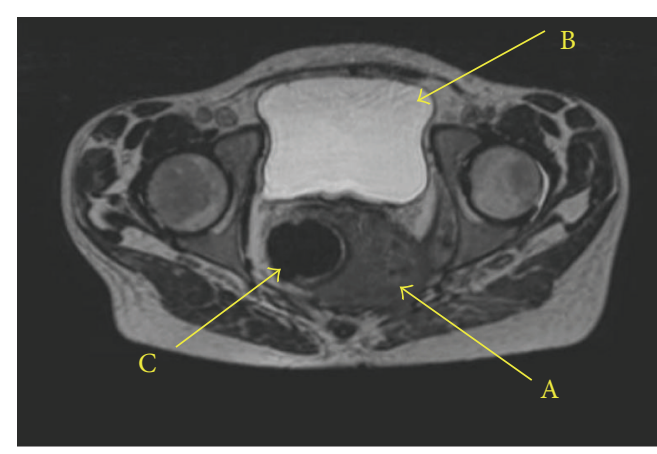

FIGURE 2: MRI scan of the small pelvic. A mass, originating from the perianal region, is expanding along the endopelvic fascia to dorsolateral with ingrowth in the left $\mathrm{m}$. obturatoria and $\mathrm{m}$. piriformis and ventral in the m. gluteus (Capitol A). No bladder ingrowth visible (Capitol B). The mass does have a direct relation with the wall of the lower rectum (Capitol C).

determining the appropriate treatment and predicting treatment outcome. When confronted with possible BLT it is very important to exclude an underlying malignancy. Other pelvic malignancies (gynaecological, gastrointestinal, and urological) should be considered, especially in younger women and patients with HPV types 16 and/or 18. In transplantation patients, posttransplant lymphoproliferative disorder should also be excluded, which was done in this patient and turned negative. In large BLTs possible sampling errors can make reliable detection of a malignancy difficult as they can contain malignant, premalignant, and/or benign cells. Also in our case only one biopsy sample revealed malignant cells. Repetitive biopsies were never able to definitely demonstrate true malignant transformation.

This report also shows that the choice of treatment is highly dependent on patient factors, such as cachexia and immune state in our patient. In this case abdominal involvement became apparent in an already advanced stage. With this paper we hope to create more awareness for the complexity of this disease and the considerations that must be taken.

A BLT is a rare condition, and, although the incidence appears to be increasing, there remains a lack of evidence on the appropriate steps to take in the treatment of these patients 


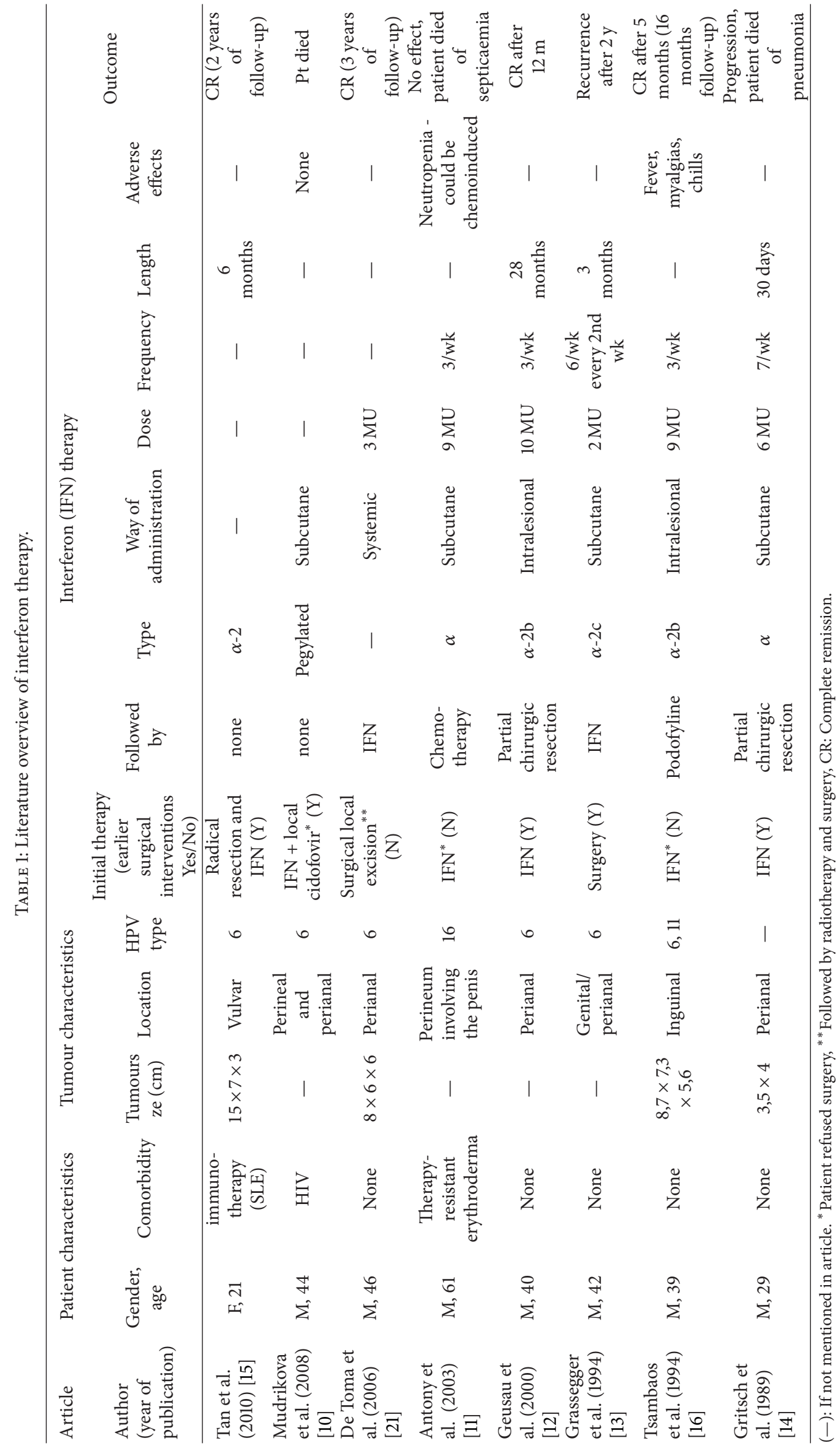


[8]. The tumour has a considerable risk of malignant transformation into fully invasive SCC or verrucous carcinomas $[1,7]$. The disease is thereby associated with high recurrence and mortality rates of, respectively, 67 and 21 percent [3]. One of the main risk factors for the development of a BLT is an immune-compromised state. The cell-mediated immune response is essential in the natural control of HPV infections $[12,22]$. Immunosuppressive drugs increase the risk of posttransplant cancer. Inparticular cyclosporines reduce UVinduced DNA repair by peripheral blood mononuclear cells $[23,24]$. Without prompt and adequate treatment of a BLT there is a risk of local invasiveness leading to various complications such as abscess formation, fistulas, and defecation problems by ingrowth in or pressure to the rectum $[3,9]$. In current literature only one case has been described with a similar intra-abdominal mass as in our patient. In this particular case extend of the disease was only detected during surgery [25]. In order to avoid this it has been suggested to perform a CT scan prior to surgery to be properly informed on the extent of the disease [26]. In this case the scan proved to be of great value.

When treatment is considered, the first choice is surgery in which a radical resection should be achieved $[3,5,8,9]$. Despite radical or wide local excision the tumour still has a high recurrence rate of 50\% [3]. The possibilities for surgery, however, are sometimes limited by factors as a poor baseline condition and advanced disease due to patient or doctors delay $[10-13,16]$. Surgical therapy often requires extensive resections by means of anterior and posterior exenteration or even a pelvectomy [12, 27].

Chemo- and/or radiotherapy have been applied in many different ways, usually following unsuccessful surgical treatments. If an underlying malignancy can be established, radioand/or chemotherapy as main treatment or prior to surgery [27-32] seem to have good results [9]. However, when used after multiple surgical interventions or as adjuvant therapy, results are less favorable $[3,33]$. The detection or exclusion of malignant transformation is essential before initiating therapy but can be very difficult to obtain. In an early stage of the disease sampling error can easily occur. Representative biopsies herein can be decisive in the establishment of a malignancy $[12,34]$. Only one report showed good results with chemoradiation as adjuvant therapy prior to surgery without first verifying a malignancy [25]. This is however a rather controversial approach and can therefore not be recommended as initial treatment.

Another controversial alternative to surgery or radiochemotherapy is the administration of interferon. Interferon has been described as a treatment for CA and BLT when other treatments have been excluded or unsuccessful. The published results with this treatment are very contradictory and vary from a complete lack of effect $[10,11,13,14,17]$ to a reduction of the disease $[12,15,16,19,35]$. A recent meta-analysis unfortunately showed no superior effect of imiquimod (interferon $\alpha$ ) compared to podophyllotoxin in the treatment of CA [20]. Only few side effects of interferon are described in literature varying from miscellaneous reactions as fever, chills, headache, myalgia's, and leucocytosis to more severe and life threatening side effects as pericarditis, autoimmune disease and myelosuppression $[16,17,19,36-38]$. When considering treatment with interferon there is a lack of consensus in dosage, frequency, and length of treatment (Table 1) [10$16,21]$. We encountered the same problem and after extensive multidisciplinary consultation decided to a dosage of $180 \mu \mathrm{g} /$ week interferon alfa $2 \mathrm{~B}$ by subcutaneous injections. As tumour reduction had been established during follow-up $\mathrm{CT}$, an appropriate dose-effect relationship was assumed. Due to the short follow-up this cannot be determined with any certainty.

This case has a few shortcomings. As mentioned in the introduction, surgery is considered first-choice treatment. Unfortunately at the time of presentation at our hospital the BLT had already grown into adjacent structures. Whether extensive resection or debulking still would have had a positive outcome cannot be assessed. Another consideration could have been to suspend all immune suppressant therapy instead of just lowering the dosage. Ceasing the prednisolone could possibly have led to a better effect of the interferon therapy and prevented the fasciitis. Furthermore, immunosuppressant drugs such as sirolimus were not considered. This could have had a positive contribution because it has antiproliferative properties. Also, considering the high costs of interferon therapy, the lack of consensus on the appropriate form of administration and dosage, and the potentially serious side effect, this certainly cannot be recommended as standard therapy.

In conclusion, we report one of the first cases of a large intra-abdominally located BLT. We have tried to provide a practical overview of current treatment options, which may benefit future patients. The outcome of each treatment depends on the disease stage, differentiation, and patient characteristics. Although in this case surgery was no longer a realistic option it should be considered the gold standard. Interferon therapy is a costly and still experimental treatment and should be regarded as a last resort. Patients should be very thoroughly informed about the potential life-threatening risks.

\section{Conflict of Interests}

The authors declare no conflict of interests.

\section{References}

[1] S. de Sanjosé, M. Diaz, X. Castellsague et al., "Worldwide prevalence and genotype distribution of cervical human papillomavirus DNA in women with normal cytology: a meta-analysis," Lancet Infectious Diseases, vol. 7, no. 7, pp. 453-459, 2007.

[2] C. S. Batista, Á. N. Atallah, H. Saconato, and E. M. da Silva, "5FU for genital warts in non-immunocompromised individuals," Cochrane Database of Systematic Reviews, vol. 4, Article ID CD006562, 2010.

[3] Q. D. Chu, M. P. Vezeridis, N. P. Libbey, and H. J. Wanebo, "Giant condyloma acuminatum (Buschke-Lowenstein tumor) of the anorectal and perianal regions: analysis of 42 cases," Diseases of the Colon and Rectum, vol. 37, no. 9, pp. 950-957, 1994.

[4] S. S. Ergün, Y. B. Kural, N. Büyükbabani, L. Verim, H. Akbulut, and L. Gürkan, "Giant condyloma acuminatum," Dermatologic Surgery, vol. 29, no. 3, pp. 300-303, 2003. 
[5] G. Sarzo, A. Del Mistro, C. Finco, H. Frayle-Salamanca, F. Marino, and M. Franzetti, "Extensive anal condylomatosis: prognosis in relation to viral and host factors," Colorectal Disease, vol. 12, pp. e128-e134, 2010.

[6] M. Scheffner, B. A. Werness, J. M. Huibregtse, A. J. Levine, and P. M. Howley, "The E6 oncoprotein encoded by human papillomavirus types 16 and 18 promotes the degradation of p53," Cell, vol. 63, no. 6, pp. 1129-1136, 1990.

[7] E. Erkek, H. Basar, O. Bozdogan, and M. C. Emeksiz, "Giant condyloma acuminata of Buschke-Lowenstein: successful treatment with a combination of surgical excision, oral acitretin and topical imiquimod," Clinical and Experimental Dermatology, vol. 34, no. 3, pp. 366-368, 2009.

[8] F. Safi, O. Bekdache, S. Al-Salam et al., "Management of perianal giant condyloma acuminatum - a case report and literature review," Asian Journal of Surgery, vol. 36, pp. 43-52, 2013.

[9] L. J. Trombetta and R. J. Place, "Giant condyloma acuminatum of the anorectum: trends in epidemiology and management. Report of a case and review of the literature," Diseases of the Colon and Rectum, vol. 44, no. 12, pp. 1878-1886, 2001.

[10] T. Mudrikova, C. Jaspers, P. Ellerbroek, and A. Hoepelman, "HPV-related anogenital disease and HIV infection: not always "ordinary" condylomata acuminata," Netherlands Journal of Medicine, vol. 66, no. 3, pp. 98-102, 2008.

[11] F. C. Antony, M. Ardern-Jones, A. V. Evans, T. Rosenbaum, and R. Russell-Jones, "Giant condyloma of Buschke-Loewenstein in association with erythroderma," Clinical and Experimental Dermatology, vol. 28, no. 1, pp. 46-49, 2003.

[12] A. Geusau, G. Heinz-Peer, B. Volc-Platzer, G. Stingl, and R. Kirnbauer, "Regression of deeply infiltrating giant condyloma (Buscheke-Lowenstein Tumor) following long-term intralesional interferon alfa therapy," Archives of Dermatology, vol. 136, no. 6, pp. 707-710, 2000.

[13] A. Grassegger, R. Hopfl, H. Hussl, K. Wicke, and P. Fritsch, "Buschke-Loewenstein tumour infiltrating pelvic organs," British Journal of Dermatology, vol. 130, no. 2, pp. 221-225, 1994.

[14] H. A. Gritsch, R. F. Randazzo, L. J. Layfield, and J. B. DeKernion, "Invasive giant condylomata acuminata: a case report," Journal of Urology, vol. 141, no. 4 I, pp. 950-952, 1989.

[15] X.-J. Tan, M. Wu, and J.-H. Lang, "Giant condyloma acuminatum of the vulva," International Journal of Infectious Diseases, vol. 14, no. 5, pp. e455-e456, 2010.

[16] D. Tsambaos, A. Monastrili, N. Kapranos, S. Georgiou, E. Pasmatzi, and H. Berger, "Intralesional interferon alpha-2b therapy for Buschke-Loewenstein tumour," Acta DermatoVenereologica, vol. 74, no. 6, pp. 457-459, 1994.

[17] J. Mendelson, A. Ferenczy, J. Arseneau et al., "Randomized placebo-controlled double-blind combined therapy with laser surgery and systemic interferon- $\alpha 2 \mathrm{a}$ in the treatment of anogenital condylomata acuminatum," Journal of Infectious Diseases, vol. 167, no. 4, pp. 824-829, 1993.

[18] J. Christophersen, E. From, F. Kristiansen et al., "Recurrent condylomata acuminata treated with recombinant interferon alpha-2a. A multicenter double-blind placebo-controlled clinical trial," Acta Dermato-Venereologica, vol. 73, no. 3, pp. 223226, 1993.

[19] A. E. Friedman-Kien, L. J. Eron, M. Conant et al., "Natural interferon alfa for treatment of condylomata acuminata," Journal of the American Medical Association, vol. 259, no. 4, pp. 533-538, 1988.

[20] J. Yan, S.-L. Chen, H.-N. Wang, and T.-X. Wu, "Meta-analysis of $5 \%$ imiquimod and $0.5 \%$ podophyllotoxin in the treatment of condylomata acuminata," Dermatology, vol. 213, no. 3, pp. 218223, 2006.

[21] G. De Toma, G. Cavallaro, A. Bitonti, A. Polistena, M. G. Onesti, and N. Scuderi, "Surgical management of perianal giant condyloma acuminatum (Buschke-Lowenstein tumor): report of three cases," European Surgical Research, vol. 38, no. 4, pp. 418-422, 2006.

[22] L. L. Villa, "Biology of genital human papillomaviruses," International Journal of Gynecology and Obstetrics, vol. 94, no. 1, pp. S3-S7, 2006.

[23] Y. Ori, M. Herman-Edelstein, B. Zingerman, B. Rozen-Zvi, U. Gafter, and T. Malachi, "Effect of immunosuppressive drugs on spontaneous DNA repair in human peripheral blood mononuclear cells," Biomedicine \& Pharmacotherapy, vol. 66, pp. 409413, 2012.

[24] F. Hinten, K. A. P. Meeuwis, M. M. van Rossum, and J. A. de Hullu, "HPV-related (pre)malignancies of the female anogenital tract in renal transplant recipients," Critical Reviews in Oncology/Hematology, vol. 84, pp. 161-180, 2012.

[25] M. G. Tytherleigh, A. J. Birtle, C. E. Cohen, R. Glynne-Jones, J. Livingstone, and J. Gilbert, "Combined surgery and chemoradiation as a treatment for the Buschke-Lowenstein tumour," Surgeon, vol. 4, no. 6, pp. 378-383, 2006.

[26] E. J. Balthazar, M. Streiter, and A. J. Megibow, "Anorectal giant condyloma acuminatum (Buschke-Loewenstein tumor): CT and radiographic manifestations," Radiology, vol. 150, no. 3, pp. 651-653, 1984.

[27] W. Haque, E. Kelly, S. Dhingra, and L. S. Carpenter, "Successful treatment of recurrent buschke-Lowenstein tumor by radiation therapy and chemotherapy," International Journal of Colorectal Disease, vol. 25, no. 4, pp. 539-540, 2010.

[28] M. W. T. Chao and P. Gibbs, "Squamous cell carcinoma arising in a giant condyloma acuminatum (Buschke-Lowenstein tumour)," Asian Journal of Surgery, vol. 28, no. 3, pp. 238-240, 2005.

[29] C. W. Sobrado, M. Mester, W. Nadalin, S. C. Nahas, S. F. Bocchini, and A. Habr-Gama, "Radiation-induced total regression of a highly recurrent giant perianal condyloma: report of a case," Diseases of the Colon and Rectum, vol. 43, no. 2, pp. 257-260, 2000.

[30] T. W. Butler, J. Gefter, and D. Kleto, "Squamous-cell carcinoma of the anus in condyloma acuminatum: successful treatment with preoperative chemotherapy and radiation," Diseases of the Colon and Rectum, vol. 30, no. 4, pp. 293-295, 1987.

[31] A. K. Ilkay, G. W. Chodak, N. J. Vogelzang, and G. S. Gerber, "Buschke-Lowenstein tumor: therapeutic options including systemic chemotherapy," Urology, vol. 42, no. 5, pp. 599-602, 1993.

[32] M. Hyacinthe, R. Karl, D. Coppola et al., "Squamous-cell carcinoma of the pelvis in a giant condyloma acuminatum: use of neoadjuvant chemoradiation and surgical resection: report of a case," Diseases of the Colon and Rectum, vol. 41, no. 11, pp. 1450$1453,1998$.

[33] A. Handisurya, A. Rieger, Z. Bago-Horvath et al., "Rapid progression of an anal Buschke-Lowenstein tumour into a metastasising squamous cell carcinoma in an HIV-infected patient," Sexually Transmitted Infections, vol. 85, no. 4, pp. 261-263, 2009.

[34] C. Parra-Herran, M. Herfs, M. Doria, C. P. Crum, and M. R. Nucci, "Giant condyloma of the cervix: an uncommon entity associated with low-risk human papilloma virus infection," American Journal of Surgical Pathology, vol. 37, pp. 300-304, 2013. 
[35] L. Risse, P. Negrier, P. M. Dang et al., “Treatment of verrucous carcinoma with recombinant alfa-interferon," Dermatology, vol. 190, no. 2, pp. 142-144, 1995.

[36] S. Sleijfer, M. Bannink, A. R. Van Gool, W. H. J. Kruit, and G. Stoter, "Side effects of interferon- $\alpha$ therapy," Pharmacy World and Science, vol. 27, no. 6, pp. 423-431, 2005.

[37] P. M. George, R. Badiger, W. Alazawi, G. R. Foster, and J. A. Mitchell, "Pharmacology and therapeutic potential of interferons," Pharmacology and Therapeutics, vol. 135, pp. 44-53, 2012.

[38] C. Popescu, V. Arama, and S. Gliga, "Acute pericarditis due to pegylated interferon alpha therapy for chronic HCV hepatitiscase report," BMC Gastroenterology, vol. 11, article 30, 2011. 


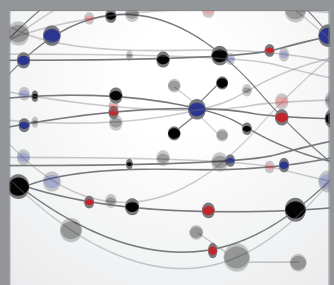

The Scientific World Journal
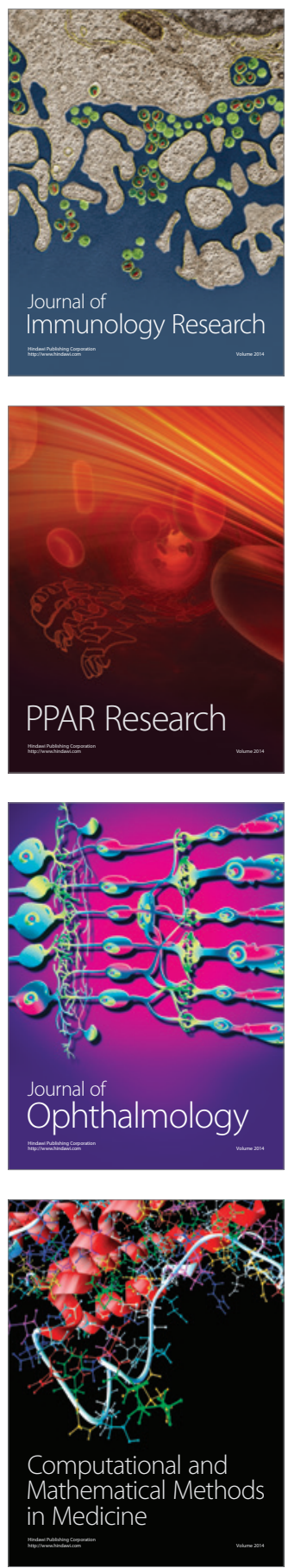

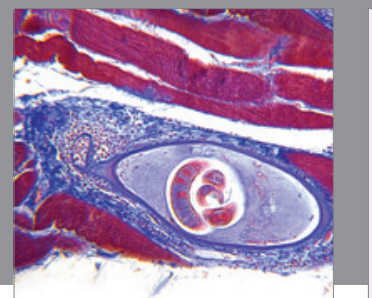

Gastroenterology

Research and Practice
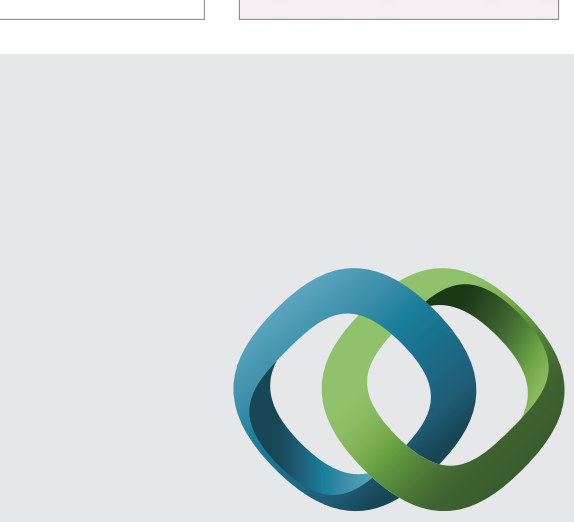

\section{Hindawi}

Submit your manuscripts at

http://www.hindawi.com
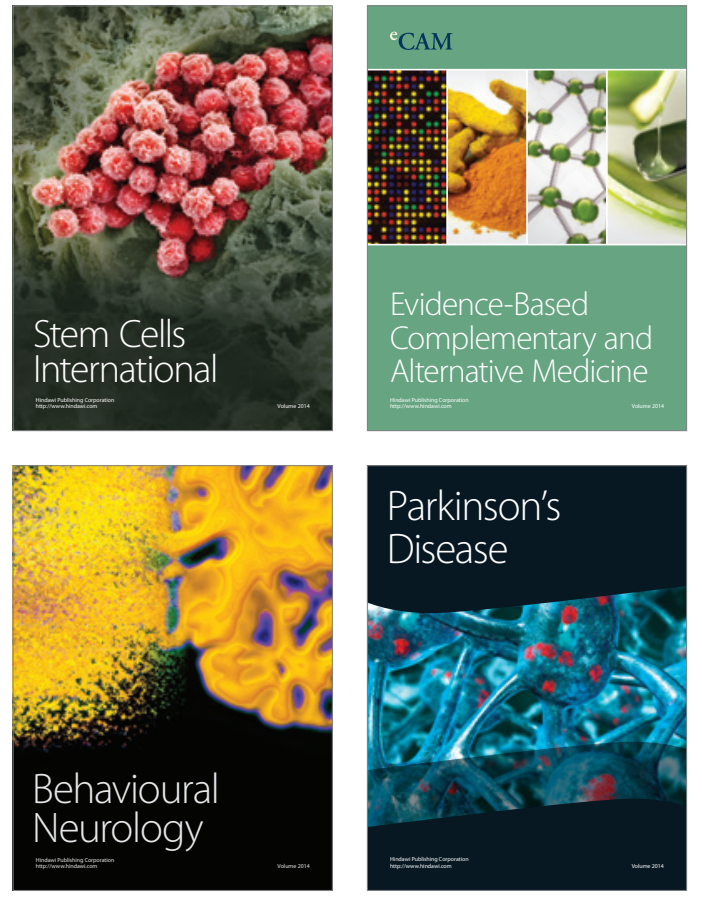
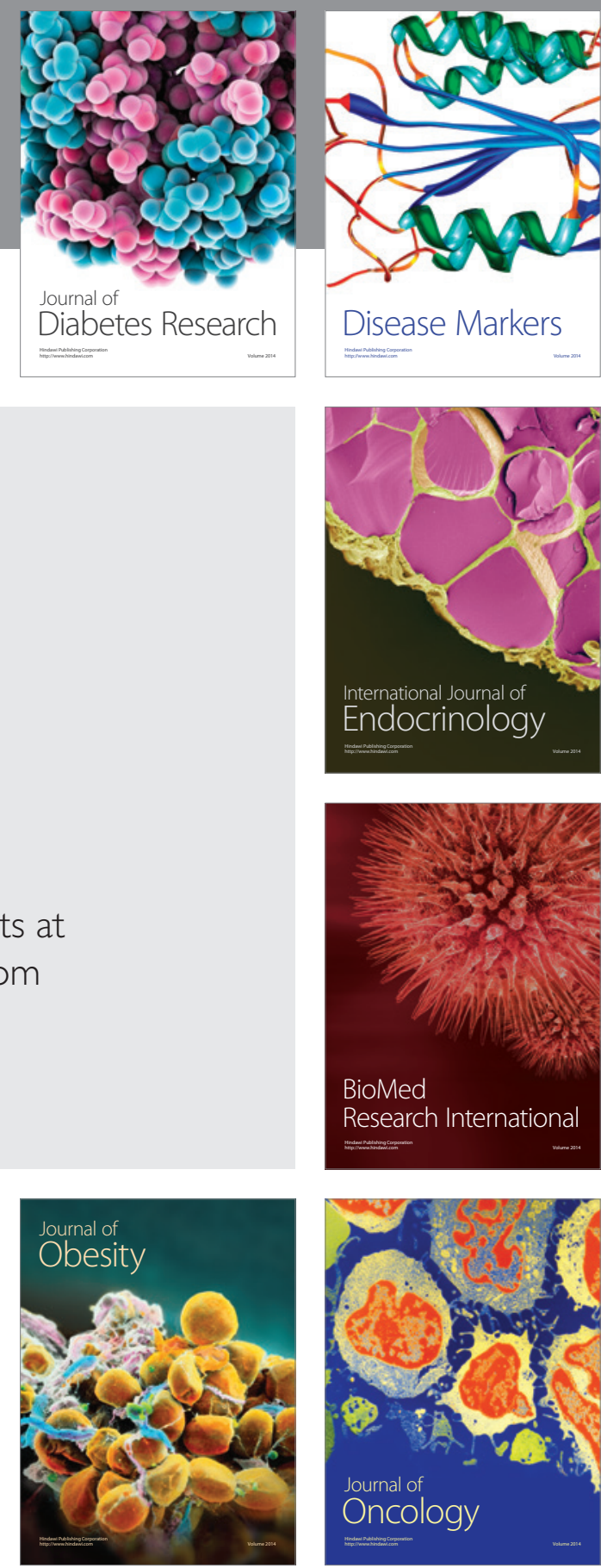

Disease Markers
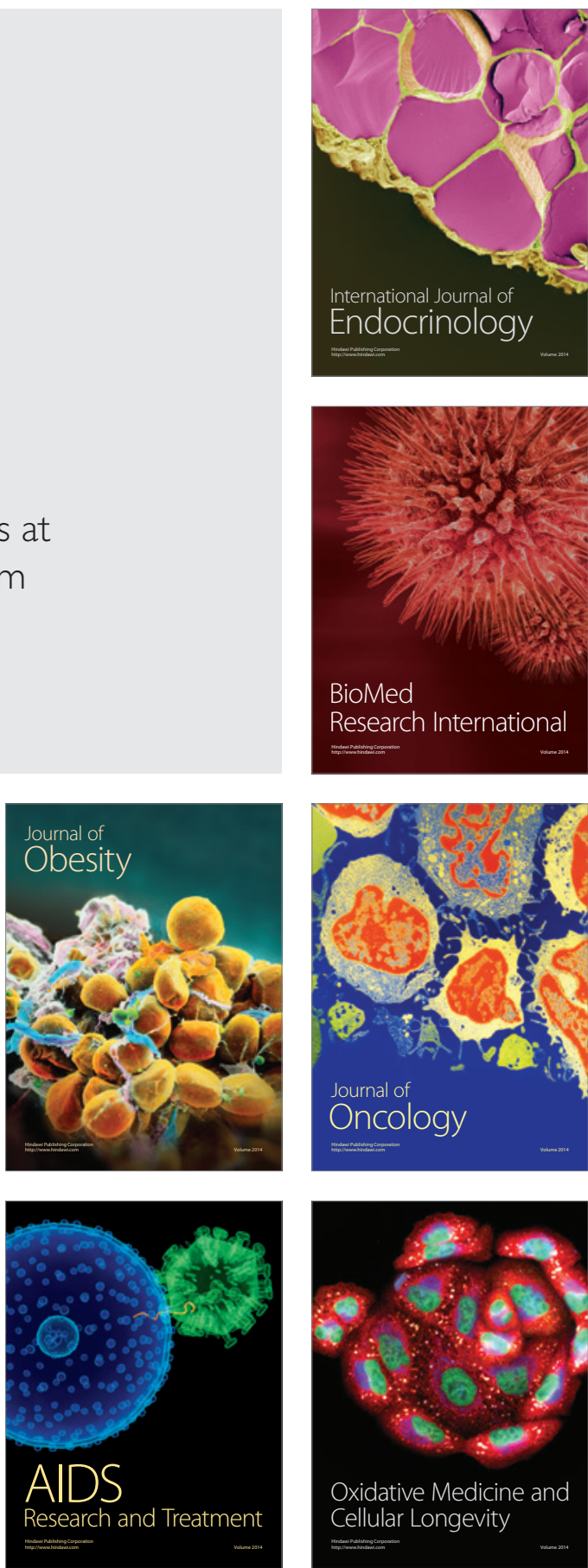